\title{
The Legal Organization of Administrative Responsibility in the Palestinian POLICE: In Accordance with Palestinian POLICE Decree No. (23) of 2017
}

\author{
ALI M.A.IQTAISH Shitao Wang \\ Linghai Road, Dalian / zip code: 116026. Dalian Maritime University- China
}

\begin{abstract}
This study seeks to clarify the administrative system of administrative accountability in the Palestinian POLICE, by clarifying the structural and procedural structure to arrive at an administrative identification, and we will work on clarifying the strengths in the POLICE decree and on clarifying the deficiencies in the Palestinian POLICE decree, We will explain what the obstacles that hindered the progress of the Palestinian POLICE are and how the Palestinian POLICE overcame and excelled from an administrative point of view, The study did not stop there. It addressed aspects of administrative grievance and administrative appeals against administrative decisions of workers in the Palestinian POLICE. It explained these procedures in line with the modern administrative vision of the Palestinian POLICE, which aims to raise the administrative system in the POLICE to the highest level of transparency and integrity following the principle Equality according to international standards.

Keywords: Administrative law, administrative responsibility, disciplinary violations, behavioral violations, administrative decision, administrative appeal, Palestinian POLICE.
\end{abstract}

DOI: $10.7176 / \mathrm{JLPG} / 96-12$

Publication date: April $30^{\text {th }} 2020$

\section{Introduction}

The executive jobs, especially the POLICE work, are among the most prominent jobs that are full of real hazards that lie in the POLICE, often dealing with the most dangerous groups of society whose character has overcome violence and resisting legal POLICE procedures in many cases, which leads to the existence of A legal case whose parties are the POLICE and the citizen with the exchange of roles between the perpetrator and the victim, legal responsibility will arise at the time, which may be imposed on the citizen when he is offended by the Policeman or imposed on the Policeman if he violates his legal powers, in the case of abuse of authority, and it is in three parts of it Civil liability, criminal liability and responsibility of the administrative.( Girod, R. J. 2013)

Some researchers in the law clarified that the definition of administrative responsibility is divided into two parts: The first is the responsibility of a person for several people, and accountability in it according to this definition is of an external nature according to following the law of the structure. This responsibility is visible to all so that a person can see their actions and results. In contrast, The second part of the definition of responsibility is a personal feeling of internal commitment, the court is internal, and its sessions are secret and judged by conscience because it occurs inside the person. ( Finer, H. 1941).

Administrative responsibility, as per the previous concept, is the backbone of administrative work in civil, military, and regular institutions. Therefore, it was necessary to organize that administrative responsibility in written laws and regulations, to ensure the ethical and administrative behavior of workers in that institution and work to develop those institutions and for there to be clarity in the administrative vision and legal procedures for these institutions, and of course we will discuss in our study on administrative responsibility For POLICE personnel. ( Kernaghan, K. 1974).

The administrative decision is the title of the administrative process that maintains administrative responsibility, where the goal of the administration in issuing the administrative decision is to achieve the administrative responsibility that aims to achieve the public interest, and this, of course, constitutes a dispute among researchers about the goal of administrative responsibility, which some believe is an administrative process that is not Except that the manager exercises his administrative powers over the employees and does not care about the public interest,(Schubert, G. A. 1957), I see the opposite. It is not acceptable for the public interest to be absent from the goals of any institution, whether it is a private or public institution, What if that institution was the (POLICE) that was established to be a garrison of public interest and public order, and this was seen, without limitation, how the Palestinian POLICE committed to fighting the Corona epidemic and was the Palestinian Policeman and still the shield of society.

Accountability in the POLICE force is the title of transparency and integrity, and this is what the Palestinian POLICE seek, There are many studies conducted in this field that raised practical and judicial issues proving the possibility of civil, criminal, and administrative responsibility for the POLICE, and described how the POLICE sought to avoid these risks, including working to establish legal advisors carefully to follow the POLICE's work to avoid making mistakes and providing direct legal advice. (Archbold, C. 2004) 
The reader may ask why the researcher chose administrative responsibility instead of discussing civil and criminal responsibility, given the fact that administrative responsibility in Palestine is covered by ambiguities and shortcomings, as civil and criminal responsibility finds, The most significant possible theoretical and practical reality on the ground, in terms of legal texts that It covers the procedures and determining the competent legal authorities to determine responsibility or not, Concerning implementation, civil and criminal responsibility has a theoretical and practical scope, as we find in Palestine the competent judiciary and its related preliminary investigation to the final investigation and the issuance of the final ruling. This is what the administrative side lacks in Palestine, and this is what I am trying to support so that this study will contribute to the progress of the administrative side in Palestine, especially in the work of the POLICE.

\section{Legal procedures before the issuance of the Palestinian POLICE decree}

Although all the theoretical procedures for all authorities in the state were parallel, civil and criminal rights procedures were faster than administrative procedures, especially concerning POLICE work, given that the POLICE apparatus originated in Palestine after the Oslo agreement in 1993 between the PLO and Israel As the POLICE work side was surrounded by many restrictions that impeded its legal progress, and are covered by time restrictions related to the time of the deployment of the security forces, where the POLICE forces were deployed about two years after the start of the agreement, and spatial restrictions, (Barak, O. 2005), where the POLICE work was initially limited to only two cities (Jericho And Gaza) from As 11 Palestinian cities. The entire city was not covered by POLICE work that was limited to Areas A, according to the agreement, provided that the Palestinian POLICE forces deployed in all areas of the West Bank and Gaza Strip after five years by the year 2000 A.D., and gradually to Areas B And C, that has not happened yet, Not to mention imposing restrictions on the human cadre and limiting it to the number of thousands of POLICEmen, and this number may not exceed and it is not sufficient for fieldwork and the development of administrative work together. ( Lia, B. 2006).

However, despite the obstacles of the occupation to prevent the progress of the Palestinian POLICE at the administrative and field levels, the POLICE began to organize their administrative affairs by relying on laws and regulations that were used before the Oslo agreement and before the birth of the idea of a Palestinian state that came into existence, Some of these laws are related to the Ottoman rule of Palestine, such as the Ottoman POLICE system 1926, which was included in its folds, especially in the text of Article 58 and what followed from how to establish administrative responsibility against POLICE personnel, but of course, this system is no longer in effect because it is not compatible with the Palestinian reality. The fact that this system, and especially the text of an article (70), made the person who decides this administrative responsibility is the investigation office only (Bureau of Investigation), as this system was marred by many deficiencies, as the decisions of the (Bureau of Investigation) are not objectionable, and its provisions are conclusive. This, of course, It does not constitute an aspect of justice for the Policeman at present, Not to mention the many shortcomings about administrative penalties that follow the report of administrative responsibility, because they did not include (average) penalties so that the system only included administrative penalties, which ranged between dismissal from service and permanent salary cuts. The system did not include temporary dismissal from service or reduced Salary temporarily, and This law was not a reliable basis for its ability to keep pace with the contemporary administrative system. (Ottoman POLICE System 1926)

At the beginning of its establishment, the Palestinian POLICE also relied on some laws issued under the British Mandate, which also included many negatives and shortcomings, as was the case in the British POLICE Law in 1936, of course, this law contained many shortcomings, but the exciting thing About the era of the British Mandate, despite the damage done to Palestine and the people of Palestine so far because of this mandate, but the British Mandate cared a lot about the administrative side of the POLICE knowledgeable in Palestine at that time, as we see that it issued a law to monitor the actions of the POLICE in 1938, As well as the laws of promotions and rewards. ( British POLICE Control Act 1938)

Where we found that during the British Mandate period, a law was issued specializing in (disciplinary crime), and a law: "the definition (of disciplinary crime) in 1941", and this law deals in the first article with the definition of disciplinary crime, which is the core of administrative accountability of POLICE personnel:

"The disciplinary crime committed by the Policeman is any behavior that shows chaos or any image that leads to harm to the POLICE force's reputation ".( The definition of disciplinary crime in 1941)

Because this law defines disciplinary crimes for POLICE officers only (43) crimes, exclusively, I consider that restricting the crime to a certain number of crimes is defective, because disciplinary crimes fall outside the scope of legality, where some of these crimes clarified the law does not define conditions as specified In the crime No. (22) stipulated (neglecting the duty), which is a broad phrase, which gives the administrative investigation office at that time and allows it to abuse the authority in the administrative investigation and allows it to use arbitrary power or also allows some to be exempt from disciplinary accountability from the punishment that leads To the corruption of the entire administrative system, In addition to the presence of illogical crimes, such as criminalizing borrowing money, among co-workers in the POLICE, Of course, not only this, but it goes beyond 
that, since the legal mandate of the British Mandate has taken care of criminality and omitted from criminalization procedures as well as penalties, and this promises, in the opinion of a fundamental defect, I advise the Palestinian legislator to delete this law because the status of the legislation card for this law according to the portal of the legal system in Palestine is valid including It does not contradict all parts of the state of Palestine.

The administrative, legal status of the POLICE continued in this case, as it relied mainly on two laws. The first is the Temporary Public Security Law No. (38) of 1965, which is a Jordanian law that was adopted and implemented during the Jordanian administration of the Palestinian (West Bank), and Law No. (6) of 1963 A.D., which was implemented. During the Egyptian administration of the Palestinian (Gaza Strip), where the main problem that the Palestinian POLICE Department faced for the entire period of enforcement of these laws after the Oslo agreement is that each of the two laws contradicts many articles regarding administrative organization in terms of procedures, punishment, and the authorities competent to impose administrative sanctions, This, of course, is not consistent with the aspirations of the Palestinian POLICE to unify administrative procedures in Palestine. ( More: Revision, Jordanian Temporary Public Security Law No. (38) of 1965, and Law No. (6) of 1963 regarding the POLICE)

The disciplinary responsibility of the POLICE force remained unclear, as it became a joint work of more than one party not specialized in POLICE science, mainly since the previous laws referred to in the previous paragraph allowed the military law to interfere and interrogate POLICE personnel, especially as stipulated in the Temporary Public Security Law No. 38 of 1965 in the matter of the POLICE, Article 87 states:

"To fulfill the purposes of this law, the provisions of the applicable military penal law shall be applied to members of the force, provided that the word (army) and the terms (military council) and (chief of staff) are replaced wherever they appear in the current law or any word or phrase that replaces them with a subsequent law with the phrase (force) General Security), (POLICE Court) and (Director of Public Security) respectively." ( Temporary Public Security Law No. 38 of 1965).

Of course, this article gave the military laws an incursion into the work of the POLICE and dealing with the POLICE force as if it were a military entity and not a civil regulatory body as is customary in most countries of the world. This gives the 1979 Penal Code and military procedures to the Palestine Liberation Organization the power to consider the POLICE officer's violations. This is what Chapter (3) stipulates in the name of military crimes, which includes sub-disciplinary crimes, instruction violations, and other disciplinary crimes in the first place and not a military crime.

The four years after the year 2000 were very destructive and cruel to the Palestinian security services, especially the Palestinian POLICE, The Israeli occupation forces rejected all agreements and understandings between them and the authority, destroyed all elements of the security services and the Palestinian POLICE, destroyed the headquarters of the POLICE and security services, killed hundreds of its members, imprisoned hundreds, confiscated their weapons and pens, and this occupying force left nothing, believing that it If the present is destroyed, there will be no future. ( Tartir, A. 2015).

This denies the allegations of the Israeli occupation and its defenders that the Palestinian POLICE have failed to establish an administrative system that allows them to control their areas of influence ( Schulze, K. E. 2001). since Israel has been trying from the first day to overthrow the signed agreements, but the methods of the Israeli occupation have not worked, because the Palestinian POLICE are the internationally recognized party. As a legal force on the Palestinian soil, it was aware of all the occupation's plans on the one hand. On the other hand, it was showing flexibility with all friendly countries to develop themselves and highlight their capabilities, which were relying only on the personal capabilities of individuals to prove their control.

In my opinion, the Israeli occupation was a mistake. The fact that the people, who have a long history spanning a hundred years of struggle and struggle, can create a secure future for future generations, After the killing and imprisonment of a large number of administrative and field staff working in the Palestinian POLICE at the hands of the occupation in 2004, And after Israel killed the late Palestinian President / Yasser Arafat after he surrounded his office with tanks, they bombed him and put poison in his food. As a result, he died in Paris on 11/11/2004. ( Froidevaux, P., others, 2016)

However, although Israel sought with all its might to end the presence of the Palestinian POLICE, on the other side some continued day and night to work to build and repair what was destroyed by the Israeli war machine, The Palestinian Legislative Council issued the first basic law (constitution) for the state of Palestine in 2002, and it was amended in 2003 and 2005, as it included for the first time special provisions related to the work of the POLICE with a pure Palestinian text, and article (82) stipulated the following:

"1- The security forces and the POLICE are a regular force, which is the armed force in the country, and its function is limited to defending the country, serving the people, protecting society, and ensuring the maintenance of security, public order, and public morals and fulfilling its duty within limits set by law in full respect of rights and freedoms. 2- The security and POLICE forces are organized by law".( Palestinian Basic Law of 2003 and its amendments).

The Palestinian Basic Law of 2003 explicitly states the need for a law to regulate the POLICE, and this is, of 
course, necessary for the POLICE, as is the case for the citizen, after that, the Council of Ministers issued a decision in 2004 to approve a security and administrative plan for the POLICE and was emphasized in the first article, including: "They need to restructure the POLICE force and work to activate it." ( Cabinet Resolution to restructure the Palestinian POLICE Service NO(98),2004)

Practical and legal steps followed this decision. Cabinet Resolution No. (94) for 2005 was issued regarding providing the Palestinian POLICE agency with equipment and staff with experience, especially in the legal field. The decision was issued to appoint (150) holders of a certificate of law in the POLICE to develop the legal and administrative work of the POLICE. ( Cabinet Resolution to restructure the Palestinian POLICE Service $\mathrm{NO}(94), 2005)$.

In fact, in 2005, the Palestinian Legislative Council passed a special law in the security forces that carry this full administrative organization of the Palestinian security services as a whole. This law treated all Palestinian security services on an equal basis, from an administrative point of view, including the Palestinian POLICE, and did not separate them. Was not aware of the fact that the nature of the work of the POLICE forces differs from other bodies, such as the civil defense, the General Intelligence Service, or the National Security Forces (the army). However, with this serious flaw in the service of law in the Palestinian security forces, the law has some advantages because it laid down the basic principles For the administrative organization of the Palestinian security services, This law established three sections of legal responsibility for workers in the security forces as a whole, namely:

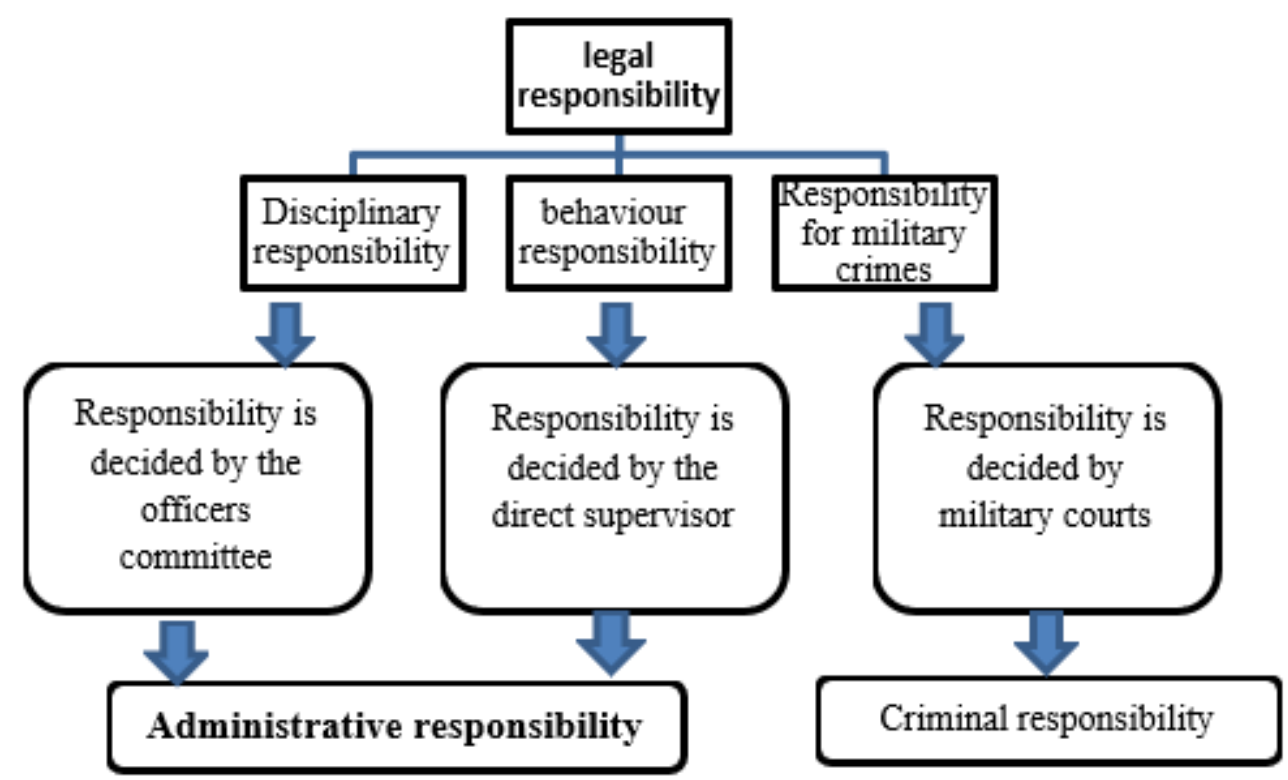

This structure that the Security Forces Service Law has followed in determining legal liability includes, as mentioned above, Administrative violations divided into two categories, the first of which are errors that do not constitute a significant defect in the work of the POLICE, and the report of administrative responsibility in it is left to the direct official, while the second category, which constitutes a fundamental imbalance in the work of the POLICE, leaving the approval of administrative responsibility in it to the officer's committee, where the law provides for the formation of its members, As for responsibility for military crimes defined in the text of the law, the law left its order to the military court, which is stipulated in the Revolutionary Law of the Palestine Liberation Organization (PLO) 1979, This law is the general basis for all administrative affairs of the security services, as this law includes a clear separation between the officers and Noncommissioned officer and organizes the administrative affairs of each of them differently from the other, Despite the positives mentioned in the law, it was comprehensive for all administrative procedures for all security agencies without distinguishing between them, without taking into account that each of them has different working conditions from the other. ( Service Law of the Palestinian Security Forces No. (8) of 2005)

Legal procedures after the issuance of the Palestinian POLICE decree:

However, the struggle of the POLICE, for autonomy and administration of its affairs, from the rest of the security services continued until it reached its goal in 2017, The first POLICE decree No. (23) was issued in 2017, This decree was based on the articles of the Basic Law 2003 and the previous laws regulating the POLICE, as well as the Revolutionary Law of the PLO 1979, and the Service Law of the Palestinian Security Forces 2005, This law gave the Higher POLICE Commission the power to prepare a structure for the POLICE. Where this law arranged the administrative organization to gain access to administrative responsibility as follows: 


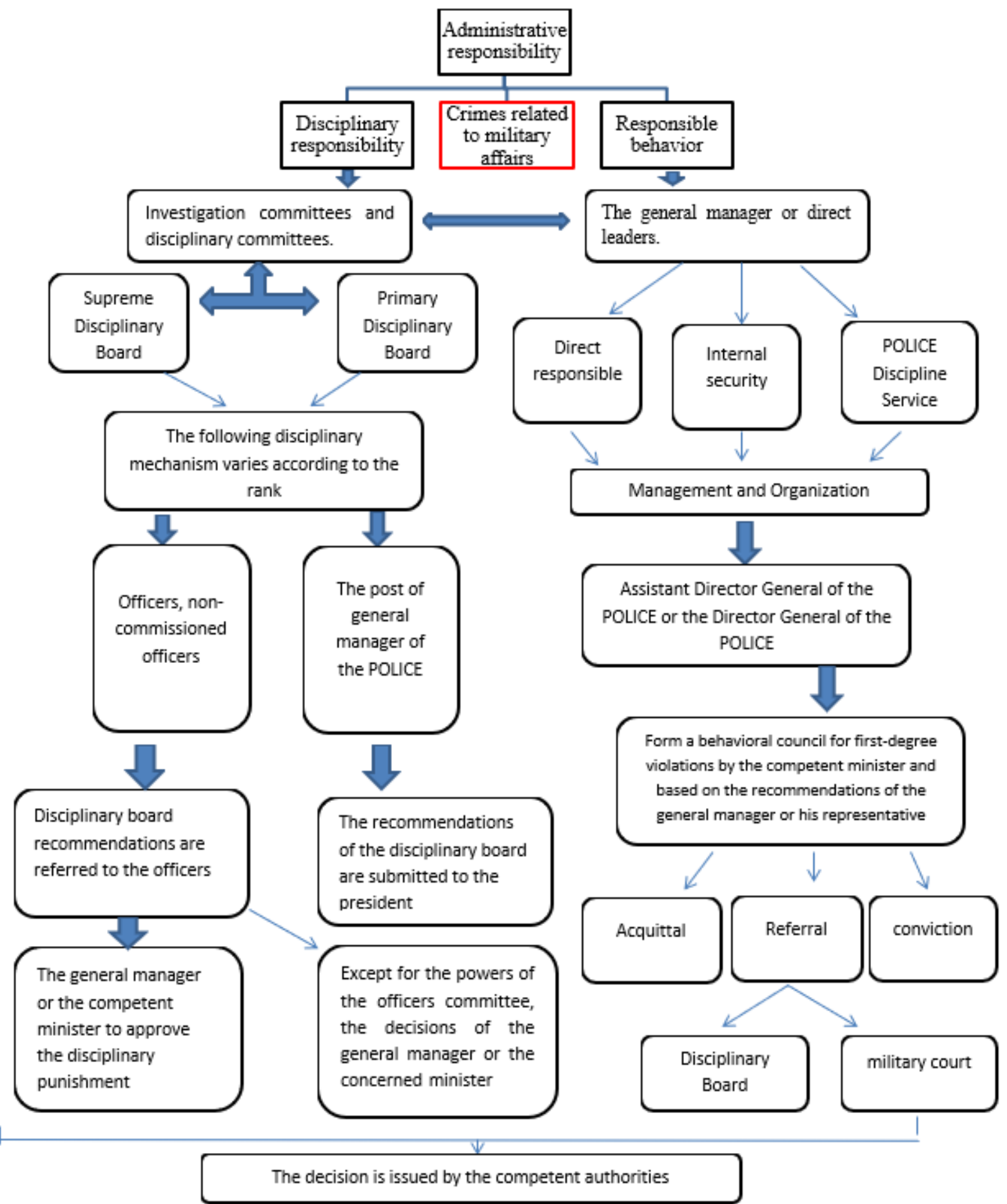

The legal organization of administrative responsibility in the 2017 POLICE decree is somewhat similar to what was stated in the Service Law in the Security Forces 2005. However, there are some additions that the POLICE Law added, so the POLICE decree followed the division of administrative responsibility into behavioral and disciplinary responsibility, because of the expanded scope of the POLICE Act of 2017 in detail on administrative responsibility, to define administrative responsibility, the work of investigative committees and disciplinary councils must be revitalized, Of course, the process of activating these committees goes through several stages, starting with the formation of disciplinary committees by order of the president if the action is against the general manager and the Minister of Interior issues it on the recommendation of the general manager in the case of accountability of the officer and the decision to form a disciplinary board issued by the minister or general manager in Accountability case noncommissioned officers, As indicated above, disciplinary boards are divided into two main parts. The first is: the Supreme Disciplinary Council considers violations of those who are 
in the rank of dean and above, and the second is the Primary Disciplinary Counsel, which specializes in accounting for those who are below the rank of dean, This is what concerns the decision to form disciplinary councils. As for the referral decision, the decision to refer to disciplinary councils is issued by the minister or the general manager, each according to his jurisdiction, and includes a statement of violations attributed to the employee, This is on an equal footing between officers and non-commissioned officers, After completing the work of disciplinary councils, these recommendations are presented to the president to ratify the punishment if these measures are taken against the director-general of the POLICE, and the results of the investigation boards are presented to the officer's committee or the general manager, While it does not fall within the competence of the officer's committee, in taking the appropriate decision if these measures were taken against the rank of officer (lieutenant and above), As for the non-commissioned officers, the recommendations of disciplinary councils or investigation committees are not considered final unless they are approved by the minister or the general manager, each within the limits of his competence. ( Palestinian POLICE Decree No. (23) of 2017)

The previous structural plan also clarified that behavioral crime procedures start from the occurrence of these violations, and are determined through the internal security of the POLICE, the official or POLICE discipline department, provided that the violation is referred after an investigation of the violating, To the administration and organization of the POLICE force, and then referred to the general manager, who in turn must acknowledge what came in the initial investigation, or recommend the formation of a behavioral council if these violations are of the first degree, based on the approval of the competent minister, The disciplinary council may investigate the violator and refer the results of the investigation with the recommendations to the general manager to issue his ruling of innocence or conviction, or refer it to the disciplinary council if the crime is disciplinary and not behavioral, or refer it to the military court if the crime is among the military crimes. (Handbook of behavioral violations of the Palestinian security forces, based on the decision of the Palestinian Prime Minister No. (193) in 2009).

Indeed, the implementation of the administrative punishment is not the end of the administrative procedures related to the administrative responsibility of the POLICE personnel, because the POLICE personnel may complain of these penalties and consider them to be unfair penalties, so there is a significant role for the administrative judiciary, so what are the procedures for challenging administrative decisions regarding the officers and non-commissioned officers in the POLICE Palestinian?

All of the above relates to the administrative structure in Palestine and is closely related to the administrative law of the POLICE, but imposing the punishment and notifying the accused is not the end of the administrative procedures, The role of the administrative judiciary (the lawsuit to cancel the administrative decision) appears, (A. Teodorescu,1926) so what are the procedures for canceling the administrative decision according to the applicable Palestinian POLICE decree?

The Palestinian POLICE Act of 2017 stipulates that if the officer or the authorized officer does not accept the administrative penalty issued against him, he must first submit an administrative complaint and submit this grievance to the direct manager who in turn sends it to the organization and administration, which in turn transmits it to the general manager, Or to submit this grievance to the Police Ombudsman and Human Rights Department, which is a department established for the POLICE to remove injustice from citizens or POLICE workers alike, The Ombudsman and the Human Rights Department shall refer this grievance with the recommendations to the Director-General for decision-making. If this grievance is accepted, the Director-General or the competent minister (the authority that issued the penalty) will issue a decision to cancel the administrative penalty. However, if this grievance is rejected, a judicial appeal may commence. (The cancellation suit), which gave the law establishing the ordinary court's jurisdiction to the Supreme Court, ( Palestinian Courts Formation Law No. (5) of 2005), This is what we will explain as follows: 


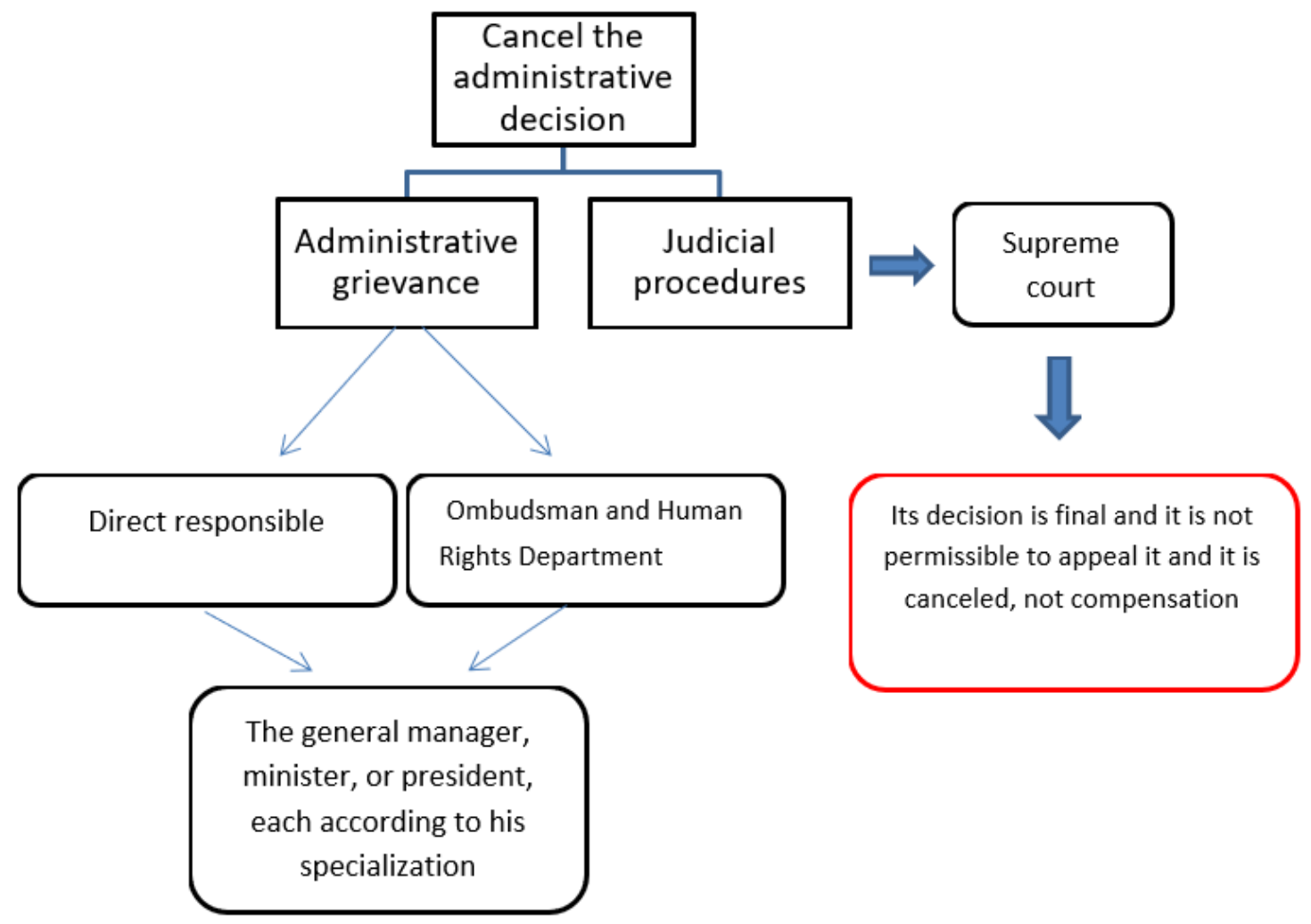

We note that the Palestinian POLICE decree has a high degree of administrative organization, to reach the administrative accountability, which leads to a reduction in corruption and transparency in the work of the POLICE, which contributes to the further development of the POLICE and the state as a whole. Moreover, because of the importance of the POLICE in the state to be neutral, impartial, and transparent, this, of course, criticizes some studies titled (Arafat POLICE) that describe the Palestinian POLICE as a group of individuals who follow the instructions of one person. He predicted that the Palestinian POLICE would not be able to survive, and they made every effort to confirm these studies in theory through the narrow exploitation of cases Individuality, This book was concluded and tried to prove that the Palestinian POLICE are fragmented and that the Palestinian POLICE depend on international humanitarian aid whose POLICE units were competing with each other to earn this aid and the POLICE leadership was not interested in administrative organization and organizational development, ( Lia, B. 2007), and practically on the ground, as mentioned above.

However, what some researchers who support the expansionist colonial thought are trying to prove, and work to support it with false facts because the facts on the ground nullify what they say, and the last of these achievements that the Palestinian POLICE are proud of is the Palestinian POLICE joining the International POLICE Organization (Interpol) in 2017, ${ }^{1}$ despite strong opposition from Israel, and this indicates the recognition of the countries of the world in the ability of the Palestinian POLICE to keep pace with international standards for administrative development, integrity, and transparency.

\section{Conclusion}

Despite the positives that the Palestinian POLICE decree of 2017 came about and the way it was organized and drawing the administrative structure to determine administrative responsibility, we have many suggestions aimed at moving forward to develop the POLICE and the administrative accountability system in it, Despite the obstacles that the occupation places in the way of the progress and development of the Palestinian POLICE, the Palestinian POLICE have emerged from the womb of suffering to put in place the most recent laws that accompany international laws agreements and standards, We find that the administrative system in the POLICE is one of the contemporary administrative systems, but this administrative system has some restrictions, due to its close association with the special laws in the rest of the Palestinian security forces and this of course is the result of the POLICE not being subject to more than a decade of the general administrative system of all security forces, and certainly affected By it and leaving, the influence on the administrative system of the POLICE, where I think that there should be more separation and allocation of administrative accountability procedures in the POLICE, as I

${ }^{1}$ https://www.interpol.int/ar/SearchPage?search=\%D9\%81\%D9\%84\%D8\%B3\%D8\%B7\%D9\%8A\%D9\%86, Last entry: 14-3-2020. 
suggest that there be a special court for the POLICE, because, it is not reasonable that when the Disciplinary Council decides that it is not competent to This crime, They are referred to the military court, regardless of their level of knowledge, but they will not have the experience required to adjudicate cases in which the Policeman is a party, as suggested by the judicial POLICE system on two levels, as is the case in Jordan, where the security law was stipulated The temporary POLICE law in 1965 and its amendments, especially the 2017 amendment, (Jordanian Temporary Public Security Law in 1965, and its amendments in 2015 and 2017), to establish a POLICE court, which specializes in the consideration of misdemeanors and crimes committed by POLICE personnel, and the amendment in 2017 provides for the establishment of a POLICE appeals court, which is competent to deal with crime cases without a misdemeanor.

It should also be noted that the system of behavioral procedures is a comprehensive and general system for all security agencies, and this leads us to the proposal to establish a list of behavioral procedures for the POLICE alone and separated from the rest of the security services, The multiplicity of bodies specialized in research and detection of behavioral violations of the POLICE is exhausting at the financial and human levels, where I propose to unify these bodies under one name with multiple specializations, instead of each working alone, like the fact that teamwork creates a kind of integration.

We also note that the law gave the Supreme Court the power to challenge administrative decisions resulting from administrative violations, and this certainly needs to be reconsidered, and work to establish an administrative court specializing in this aspect without other courts, and this complies with the provisions of the Palestinian Basic Law 2003 and its amendments, We also seek that the administrative judiciary is also on two levels, not only to cancel the administrative decision but also to include compensation.

As for the disciplinary aspect, I suggest that there be effective oversight and that this be done through the formation of a disciplinary body to decide administrative decisions before judicial appeals therein, and this has a significant role in limiting administrative cases such as before the administrative court.

I propose to the Palestinian Legislative Council (the Legislative Authority) to take the recommendations mentioned in this scientific paper, as they are essential in the legal progress of the police, and he proposed to accelerate the raising of the legal degree of the current decree to the rank of ordinary laws following constitutional rules.

\section{References}

Archbold, C. (2004). POLICE accountability, risk management, and legal advising (p. 51). LFB Scholarly Pub. A.Teodorescu, Administrative law treaty, volume I, third edition, (Institute of Graphic Arts „Eminescu” S.A., 1929).

Barak, O. (2005). The failure of the Israeli-Palestinian peace process, 1993-2000. Journal of Peace Research, 42(6), 719-736,p733.

British POLICE Control Act 1938.

Cabinet Resolution to restructure the Palestinian POLICE Service NO(98),2004.

Cabinet Resolution to restructure the Palestinian POLICE Service NO(94),2005

Finer, H. (1941). Administrative responsibility in democratic government. Public administration review, 1(4), 335 350.

Froidevaux, P., Bochud, F., Baechler, S., Castella, V., Augsburger, M., Bailout, C., ... \& Uldin, T. (2016). 210Po poisoning as a possible cause of death: forensic investigations and toxicological analysis of the remains of Yasser Arafat. Forensic science international, 259, 1-9.

Girod, R. J. (2013). POLICE liability and risk management: Torts, civil rights, and employment law. CRC Press, pp xix.

Handbook of behavioral violations of the Palestinian security forces, based on the decision of the Palestinian Prime Minister No. (193) in 2009.

https:/www.interpol.int/ar/SearchPage?search=\%D9\%81\%D9\%84\%D8\%B3\%D8\%B7\%D9\%8A\%D9\%86, Last entry: 3-14-2020.

Jordanian Temporary Public Security Law in 1965, and its amendments in 2015 and 2017.

Kernaghan, K. (1974). Codes of ethics and administrative responsibility. Canadian public administration, 17(4), 527-541.

Lia, B. (2006). A POLICE force without a state: A history of the Palestinian security forces in the West Bank and Gaza. ISBS

More: Revision, Jordanian Temporary Public Security Law No. (38) of 1965, and Law No. (6) of 1963 regarding the POLICE.

Ottoman POLICE System 1926.

Palestinian Courts Formation Law No. (5) of 2005.

Palestinian POLICE Decree No. (23) of 2017.

Schubert, G. A. (1957). "The public interest" in administrative decision-making: Theorem, theosophy, or theory?. 
American Political Science Review, 51(2), 346-368.

Schulze, K. E. (2001). Camp David and the Al-Aqsa Intifada: an assessment of the state of the Israeli-Palestinian peace process, July-December 2000. Studies in Conflict \& Terrorism, 24(3), 215-233.

Service Law of the Palestinian Security Forces No. (8) of 2005

The definition (of disciplinary crime) in 1941.

Temporary Public Security Law No. 38 of 1965.

Tartir, A. (2015). The evolution and reform of Palestinian security forces 1993-2013. Stability: International Journal of Security and Development, 4(1). 